\title{
Objective Assessment of Spasticity by Pendulum Test: A Systematic Review on Methods of Implementation and Outcome Measures
}

Fariborz Rahimi ( $\nabla$ frahimi@ubonab.ac.ir)

University of Bonab https://orcid.org/0000-0001-6689-8210

Reza Eyvazpour

University of Tabriz

Nazila Salahshour

University of Bonab

Mahmood Reza Azghani

Sahand University of Technology

Research article

Keywords: Spasticity, Wartenberg pendulum test, objective assessment, outcome measure

Posted Date: May 11th, 2020

DOI: https://doi.org/10.21203/rs.3.rs-27274/v1

License: (c) (i) This work is licensed under a Creative Commons Attribution 4.0 International License.

Read Full License

Version of Record: A version of this preprint was published at BioMedical Engineering OnLine on November 9th, 2020. See the published version at https://doi.org/10.1186/s12938-020-00826-8. 


\section{Abstract}

Background:Instrumented pendulum test is an objective and repeatable biomechanical method of assessment for spasticity. However, multitude of sensor technologies and plenty of suggested outcome measures, confuse those interested in implementing this method in practice. Lack of a standard agreement on the definition of outcome measures adds to this ambiguity. In this systematic review of studies, we aim to reduce the confusion by providing pros and cons of the available choices, and also by standardizing the definitions.

Methods:A literature search was conducted for the period of 1950 to the end of 2019 on PubMed, Science Direct, Google Scholar and IEEE explore; with keywords of "pendulum test" and "Spasticity".

Results:Twenty-eight studies with instrumented pendulum test for assessment of spasticity met the inclusion criteria. All the suggested methods of implementation were compared and advantages and disadvantages were provided for each sensor technology. An exhaustive list categorized outcome measures in three groups of angle-based, angular velocity-based, and angular acceleration-based measures with all different names and definitions.

Conclusions:From a critical point of view, sources of ambiguity were found and explained with the help of graphical representation of pendulum movement stages and corresponding parameters on the angular waveforms. We hope using the provided tables simplify the choices when implementing pendulum test for spasticity evaluation, improve the consistency when reporting the results, and disambiguate inconsistency in the literature.

\section{Background}

Spasticity according to European Thematic Network to Develop Standardized Measures of Spasticity is "disordered sensory-motor control, resulting from an upper motor neuron lesion, presenting as intermittent or sustained involuntary activation of muscles" [1]. This complex motor disorder which is caused by diverse sources of upper motor neuron lesions, affects patients with stroke[2], spinal cord injury [3], traumatic brain injury[4], multiple sclerosis[5] and cerebral palsy[6]. Spasticity can create severe pain and hence may negatively affect the quality of life. Spasticity can interfere with movement and can lead to stiff, painful joints $[7,8]$. This disorder affects more than 12 million persons in the world and interferes with the natural movements of the patients $[9,10]$. Billions of dollars are spent in pharmaceutical industry in order to develop anti-spasticity drugs, though lack of repeatable and objective outcome measures hinders the success[8]. It is generally agreed that spasticity is easy to recognize, but not so easy to quantify. Quantitative assessment of spasticity and spasms is crucial in evaluating treatment interventions. Although quantitative clinical scales have been proposed and are currently in use[11-14], but they lack objectivity.

To overcome objectivity issue, one of the promising methods that was introduced about 70 years ago 
are still missing. Many attempts can be found in the literature that aimed at providing instrumented pendulum test of spasticity[16-18]. Still, when it comes to methods of implementation and choice of outcome measures, the literature is very diverse and at times non-consistent. This makes practical use of the published research difficult, particularly for those who want to actually implement this method. Although Review studies can be found on pendulum test of spasticity, they have mainly focused on psychometric properties of this method[19, 20]. In this article we have exhaustively searched the published scientific literature in order to come up with a clear list of options for practical methods of implementation. We have further tried to disambiguate available choices of outcome measures for pendulum test of spasticity.

\section{Methods}

\subsection{Search strategy}

A systematic review was conducted to identify literature published in four international databases between 1950 and the end of 2019: PubMed, Science Direct, Google Scholar and IEEE explore. Science Direct database was available from 1995 and hence was searched from 1995 to 2019. Combining the keywords "pendulum test" and "Spasticity" is defined as the search strategy. No filters were applied on the type of disease, because it was not the focus of study. The search strategy was the same in all databases, with modifications to fit the web interfaces. Figure 1 shows the search strategy and selection process.

\subsection{Study selection and eligibility criteria}

After excluding duplicates, the selection of studies was carried out in two stages. All the remained articles were screened first by title and abstract, and then by full text for eligibility. At least one of the mentioned sections should include both "pendulum test" and "spasticity", and also there should be a mention of quantitative/objective assessment, or instrument/sensor, or outcome measure. In other words, pure clinical studies with no quantitative evaluation of spasticity were excluded.

\section{Results}

\subsection{Description of studies}

As summarized in Fig. 1, initial search provided 1575 articles. After removing duplicates, 1551 articles remained from which 1456 were excluded because of not being eligible by examining the title and abstract. From the remaining 95 articles, 70 were removed based on full text assessment for eligibility. Three more relevant studies were found through the articles' references. Therefore, 28 articles met the eligibility criteria and were included in the review (Table 3 ). 
Table 3

Summary of the studies and technological implementation of Wartenberg's pendulum test

\begin{tabular}{|c|c|c|c|c|}
\hline Author/Year & joint & $\begin{array}{l}\text { People under study } \\
\text { (number of participants) }\end{array}$ & Main technology & $\begin{array}{l}\text { Compared } \\
\text { to Clinical } \\
\text { Scale }\end{array}$ \\
\hline \multirow[t]{2}{*}{ Couvée,1968[32] } & Knee & Paraplegia $(\mathrm{N}=6)$ & Potentiometer & NC \\
\hline & & Healthy $(\mathrm{N}=5)$ & & \\
\hline \multirow[t]{2}{*}{ Bajd,1984[33] } & Knee & $\operatorname{SCl}(N=10)$ & Electro goniometer & NC \\
\hline & & Hemiplegics $(\mathrm{N}=5)$ & Tachometer & \\
\hline Leslie,1992[34] & Knee & $\mathrm{MS}(\mathrm{N}=14)$ & Electro goniometer & AS \\
\hline $\begin{array}{l}\text { Stillman,1995 } \\
\text { [18] }\end{array}$ & Knee & $\begin{array}{l}\text { Healthy Young, Middle } \\
\text { aged, Elderly }(\mathrm{N}=77)\end{array}$ & Video camera & NC \\
\hline $\mathrm{He}, 1997[35]$ & Knee & $\mathrm{MS}(\mathrm{N}=46)$ & Electro goniometer & NC \\
\hline \multirow[t]{2}{*}{ Kaeser,1998[36] } & Knee & Healthy $(N=40)$ & Electro goniometer & AS \\
\hline & & Spastic $(\mathrm{N}=9)$ & Ultrasound & \\
\hline \multirow{2}{*}{$\begin{array}{l}\text { Greenan Fowler, } \\
2000 \text { [6] }\end{array}$} & Knee & $\mathrm{CP}(\mathrm{N}=30)$ & Electro goniometer & MAS \\
\hline & & Healthy $(N=10)$ & & \\
\hline \multirow{2}{*}{$\begin{array}{l}\text { Cavorzin,2001 } \\
\text { [37] }\end{array}$} & Knee & Spastic $(\mathrm{N}=15)$ & Potentiometer & AS \\
\hline & & Healthy $(\mathrm{N}=10)$ & Electromyography & \\
\hline \multirow{2}{*}{$\begin{array}{l}\text { Nordmark,2002 } \\
\text { [16] }\end{array}$} & Knee & $C P(S D R)(N=20)$ & Electro goniometer & MAS \\
\hline & & & EMG & \\
\hline \multirow[t]{2}{*}{ Lin, 2003 [38] } & Elbow & Stroke $(N=11)$ & Electro goniometer & AS \\
\hline & & Healthy $(N=11)$ & Electromyography & \\
\hline \multirow{2}{*}{$\begin{array}{l}\text { Syczewska,2009 } \\
\text { [27] }\end{array}$} & Knee & $\mathrm{CP}(\mathrm{N}=21)$ & Vicon Motion Capture & NC \\
\hline & & Trauma $(\mathrm{N}=6), \mathrm{DS}(\mathrm{N}=3)$ & ENG & \\
\hline $\begin{array}{l}\text { Bohannon,2009 } \\
\text { [39] }\end{array}$ & Knee & Chronic stroke $(\mathrm{N}=8)$ & $\begin{array}{l}\text { Polhemus Liberty magnetic } \\
\text { position tracking system }\end{array}$ & AS \\
\hline \multirow[t]{2}{*}{ Sterpi, 2013 [17] } & Knee & $\begin{array}{l}\text { Severe cerebral lesion }(\mathrm{N} \\
=11)\end{array}$ & $\begin{array}{l}\text { inertial sensor } \\
\text { (Accelerometer, Gyroscope, } \\
\text { Magnetometer) }\end{array}$ & MAS \\
\hline & & healthy $(\mathrm{N}=10)$ & & \\
\hline $\begin{array}{l}\text { Tancredo,2013 } \\
\text { [29] }\end{array}$ & Knee & $\mathrm{SCl}(\mathrm{N}=11)$ & $\begin{array}{l}\text { Accelerometer, Electro } \\
\text { goniometer }\end{array}$ & MAS \\
\hline Lemovne.2013 & Ankle & Healthv $(\mathrm{N}=1)$ & Accelerometer(IPhone & NC \\
\hline \multicolumn{3}{|c|}{ Loading [MathJax]/jax/output/CommonHTML/fonts/TeX/fontdata.js } & wireless) & \\
\hline
\end{tabular}




\begin{tabular}{|c|c|c|c|c|}
\hline Author/Year & joint & $\begin{array}{l}\text { People under study } \\
\text { (number of participants) }\end{array}$ & Main technology & $\begin{array}{l}\text { Compared } \\
\text { to Clinical } \\
\text { Scale }\end{array}$ \\
\hline $\begin{array}{l}\text { Azevedo,2013 } \\
\text { [41] }\end{array}$ & Knee & $\operatorname{SCl}(\mathrm{N}=5)(5 \mathrm{Time})$ & Electro goniometer & NC \\
\hline \multirow[t]{2}{*}{ Szopa,2014 [42] } & \multirow[t]{2}{*}{ Knee } & $\mathrm{CP}(\mathrm{N}=36)$ & \multirow[t]{2}{*}{ Accelerometer } & \multirow[t]{2}{*}{ DAROM } \\
\hline & & Healthy $(N=18)$ & & \\
\hline \multirow[t]{2}{*}{ Yeh,2016 [43] } & \multirow[t]{2}{*}{ Knee } & Stroke $(N=13)$ & Electro goniometer (Two) & \multirow[t]{2}{*}{ MAS } \\
\hline & & Healthy $(\mathrm{N}=3)$ & Gyroscope (Wii remote) & \\
\hline \multirow{2}{*}{$\begin{array}{l}\text { Vargas } \\
\text { Luna,2016 [44] }\end{array}$} & \multirow[t]{2}{*}{ Knee } & \multirow[t]{2}{*}{$\operatorname{SCl}(\mathrm{N}=4)$} & Goniometer & \multirow[t]{2}{*}{ AIS } \\
\hline & & & Video tracking & \\
\hline \multirow[t]{2}{*}{ Bui,2017 [45] } & \multirow[t]{2}{*}{ Knee } & ARSACS (N = 13) & Gyroscope & \multirow[t]{2}{*}{ MAS } \\
\hline & & Healthy $(\mathrm{N}=32)$ & Accelerometer & \\
\hline \multirow{4}{*}{$\begin{array}{l}\text { Popovic- } \\
\text { Maneski,2017 } \\
{[46]}\end{array}$} & \multirow[t]{4}{*}{ Knee } & Chronic $\mathrm{SCI}(\mathrm{N}=2)$ & Accelerometers (two) & \multirow[t]{4}{*}{ MAS } \\
\hline & & Healthy $(\mathrm{N}=5)$ & Gyroscope & \\
\hline & & & Encoder (Hall-effect) & \\
\hline & & & EMG & \\
\hline \multirow{4}{*}{$\begin{array}{l}\text { Popovic- } \\
\text { Maneski,2018 } \\
{[47]}\end{array}$} & \multirow[t]{4}{*}{ Knee } & $\operatorname{SCl}(\mathrm{N}=9)$ & Absolute joint angle & \multirow[t]{4}{*}{ AS } \\
\hline & & Healthy $(N=6)$ & encoder & \\
\hline & & & Gyroscope & \\
\hline & & & EMG Electrode & \\
\hline \multirow{2}{*}{$\begin{array}{l}\text { Aleksić,2018 } \\
\text { [47] }\end{array}$} & \multirow[t]{2}{*}{ Knee } & $\operatorname{SCl}(n=1)$ & Marker-based system & \multirow[t]{2}{*}{ NC } \\
\hline & & Healthy $(\mathrm{N}=1)$ & $\begin{array}{l}\text { Joint angle encoder and } \\
\text { IMU }\end{array}$ & \\
\hline \multirow{4}{*}{$\begin{array}{l}\text { Popović, } 2018 \\
\text { [48] }\end{array}$} & \multirow[t]{4}{*}{ Knee } & \multirow{4}{*}{$\begin{array}{l}\text { humans with the central } \\
\text { nervous system (CNS) } \\
\text { lesion }\end{array}$} & Accelerometers (two) & \multirow[t]{4}{*}{ AS } \\
\hline & & & Gyroscope & \\
\hline & & & Encoder (Hall-effect) & \\
\hline & & & EMG & \\
\hline
\end{tabular}




\begin{tabular}{|lllll|}
\hline Author/Year & joint & $\begin{array}{l}\text { People under study } \\
\text { (number of participants) }\end{array}$ & Main technology & $\begin{array}{l}\text { Compared } \\
\text { to Clinical } \\
\text { Scale }\end{array}$ \\
\hline $\begin{array}{l}\text { Whelan,2018 } \\
{[49]}\end{array}$ & Knee & $\mathrm{ABI}(\mathrm{N}=45)$ & $\begin{array}{l}\text { Fiber-optic goniometer } \\
(\mathrm{FOG})\end{array}$ & MAS \\
& & $\mathrm{MS}(\mathrm{N}=14)$ & & \\
& $\mathrm{CP}(\mathrm{N}=12)$ & & \\
& $\mathrm{SCl}(\mathrm{N}=22)$ & & \\
\hline
\end{tabular}

\subsection{Assessment of spasticity}

Methods of assessment of spasticity can be broadly categorized into clinical, biomechanical, and electrophysiological[21]methods. Clinical methods, that are gold standards in clinic routines, are semiqualitative. Although clinical scales have been proposed to provide quantitative outcomes, they suffer from lack of objectivity. Biomechanical and electrophysiological methods involve sensors or instruments and can provide objective outcome measures.

A handful of clinical measures such as (CSI: composite spasticity index[22], HAT: hypertonia assessment tool[23], and TSS: triple spasticity scale[24], etc.) have been proposed and used in clinical assessments. However, the most routine method of assessment of spasticity by clinicians are the following four scales that are compared in detail in Table 1, Table 2: Ashworth Scale (AS)[11], Modified Ashworth Scale (MAS) [12], Tardieu Scale (TS)[13], and Modified Tardieu Scale (MTS)[14].

Table 2

Comparison of Tardieu and Modified Tardieu scales

\begin{tabular}{|c|c|c|}
\hline Score & TS[13] & $\begin{array}{l}\text { Changed in: } \\
\text { MTS[14] }\end{array}$ \\
\hline 0 & No resistance throughout the course of the passive movement & No change \\
\hline 1 & Slight resistance throughout the course of passive movement & No Change \\
\hline 2 & $\begin{array}{l}\text { Clear catch at precise angle, interrupting the passive movement, following } \\
\text { by release }\end{array}$ & No Change \\
\hline 3 & $\begin{array}{l}\text { Unsustained clonus(less than } 10 \mathrm{sec} \text { when maintaing the pressure) } \\
\text { occurring at a precise angle, followed by release }\end{array}$ & No Change \\
\hline 4 & $\begin{array}{l}\text { sustained clonus(more than } 10 \mathrm{sec} \text { when maintain the pressure) occurring } \\
\text { at a precise angle, followed by release }\end{array}$ & No Change \\
\hline 5 & Joint is immovable & No Change \\
\hline
\end{tabular}

All these scales assess spasticity by manual estimation of increased resistance of specific muscle groups to passive motion. From historical point of view, in 1954 Tardieu et al. introduced a 6-point scale to assess spasticity for the first time which was speed dependent. 
A decade after that and independently, in 1964, Ashworth proposed a 5-point scale which did not take the velocity dependence of spasticity into account. This scale was modified in 1987 by Bohannon and Smith to deal with the accumulation of most of the scores towards the lower end of the scale. They performed this by including an extra category $(1+$, Table 1$)$, making it a 6-point scale, and also modified the definitions slightly. In 1999, Boyd and Graham tried to standardize procedure of spasticity assessment and provided the modified TS (kept the 6-point system). MTS quantifies two angles: angle of 'catch' (stretch reflex threshold, measured at high speed) and the full range of motion (ROM, an angle measured at low speed). The difference between the two angles is suggested to be an indication of dynamic spasticity (dynamic tone).

Table 1

Comparison of Ashworth and Modified Ashworth scales

\begin{tabular}{|lll|}
\hline Score & AS[11] & Changed in:[12] \\
\hline 0 & No increase in tone & No change \\
\hline $1+$ & $\begin{array}{l}\text { Slight increase in tone } \\
\text { manifested by a "catch" when } \\
\text { the limb is moved in } \\
\text { flexion/extension }\end{array}$ & $\begin{array}{l}\text { Slight increase in tone manifested by a catch, release or } \\
\text { minimal resistance at the end of range of motion(ROM) } \\
\text { when the limb is moved in flexion/extension }\end{array}$ \\
\hline 2 & $\begin{array}{l}\text { More marked increase in tone, } \\
\text { but the limb is easily moved } \\
\text { through its full ROM }\end{array}$ & $\begin{array}{l}\text { Slight increase in tone manifested by a catch, followed } \\
\text { by minimal resistance throughout the remainder(less } \\
\text { than half)of ROM }\end{array}$ \\
\hline 3 & $\begin{array}{l}\text { Considerable increase in tone- } \\
\text { passive movement difficult }\end{array}$ & No Change \\
\hline 4 & $\begin{array}{l}\text { Limb rigid in flexion and } \\
\text { extension }\end{array}$ & No Change \\
\hline
\end{tabular}

Table 1 compares clinical evaluation and scores of spasticity by Ashworth and modified Ashworth scales. Table 2 demonstrates the method of clinical evaluation of spasticity by both Tardieu and modified Tardieu scales. The differences are only in performing the test and interpretation of the results. For passive stretch in MTS only two speeds are utilized. At slow speed, passive range of motion is found as an angle; and at fast speed, spastic reaction is evaluated as another angle. The difference between these two angles is the true measure of dynamic spasticity.

Objective and quantitative assessment methods make evaluation independent of individual judgement and often increase the sensitivity. They resolve the issues of inter- and intra-rater variability as well. From objective and quantitative methods of spasticity assessment, in this review, we focus on one of the most popular biomechanical methods which is pendulum test. 
Introduced in 1951 Wartenberg's pendulum test was designed to objectively assess knee spasticity in a free oscillation when the leg is first raised to horizontal position and then dropped[15]. This test is subjective, simple and quick to implement, reproducible, non-invasive, and is non-intimidating to the children or individuals with cognitive impairments. However, it has its own shortcomings. For example, the results are completely affected by the level of relaxation and by the form of sitting. This test was initially aimed explicitly at the lower limb, but modified versions were later used for upper extremities as well. Boczko et al.[25] modified it in 1958 as an instrumented test with a flashlight and camera to capture the trace of oscillation. Later, many sensor technologies have been used in instrumented pendulum test (Table 4). The common procedure to perform this test starts with the participant sitting in a relaxed position and the leg to test hanging freely over the edge of a seat or a table (Fig. 2). Then the examiner lifts the leg to a horizontal position and lets it swing freely. From this free oscillation, many measures can be extracted to quantify the level of spasticity. Since the test accuracy depends completely on the relaxation of the leg being tested (no voluntary muscle contraction), methods of confirmation of relaxation have been proposed. The two common methods are using Electromyography (EMG)[6, 9], and using phase plane diagram of angle versus angular velocity[26]. Numerous studies have reported the validity and repeatability of this biomechanical test in diverse groups of patients[10, 17, 27]. 
Table 4

Summary of the popular Technologies used in objective pendulum test, and their advantages and shortcomings

\begin{tabular}{|c|c|c|}
\hline Technology & Advantage & Disadvantage \\
\hline \multirow[t]{2}{*}{$\begin{array}{l}\text { Potentiometer } \\
\text { (Angle) }\end{array}$} & \multirow[t]{2}{*}{ Simple, low cost and suitable for online computer analysis[33]. } & $\begin{array}{l}\text { Higher errors; } \\
\text { lower stability; } \\
\text { difficult to } \\
\text { attach \& } \\
\text { hindering knee- } \\
\text { joint motion[28] }\end{array}$ \\
\hline & & $\begin{array}{l}\text { Need for } \\
\text { differentiation to } \\
\text { get angular } \\
\text { velocity / } \\
\text { acceleration[51] }\end{array}$ \\
\hline \multirow[t]{2}{*}{$\begin{array}{l}\text { Goniometer } \\
\text { (Angle) }\end{array}$} & \multirow[t]{2}{*}{ Easy to attach[51] } & $\begin{array}{l}\text { Questionable } \\
\text { reliability, cause } \\
\text { of high } \\
\text { individual } \\
\text { errors[52] }\end{array}$ \\
\hline & & $\begin{array}{l}\text { Errors of joint } \\
\text { repositioning[53] }\end{array}$ \\
\hline $\begin{array}{l}\text { Electro- } \\
\text { goniometer } \\
\text { (Angle) }\end{array}$ & High reliability[51] & $\begin{array}{l}\text { large non- } \\
\text { linearity and } \\
\text { hysteresis[51] }\end{array}$ \\
\hline \multirow[t]{2}{*}{$\begin{array}{l}\text { Accelerometer } \\
\text { (Linear } \\
\text { acceleration) }\end{array}$} & $\begin{array}{l}\text { Stable and easy to attach. high sensitivity and excellent } \\
\text { reliability of the pendulum test[42] }\end{array}$ & \multirow{2}{*}{$\begin{array}{l}\text { less accurate } \\
\text { angle estimation } \\
\text { during } \\
\text { movement[53] }\end{array}$} \\
\hline & less expensive; not restricting the movement[51] & \\
\hline $\begin{array}{l}\text { Gyro (Angular } \\
\text { velocity) }\end{array}$ & $\begin{array}{l}\text { No need for numerical differentiation; sufficient accuracy; low } \\
\text { susceptibility to effects from the motion of the knee joint axis; } \\
\text { no restriction of the knee joint when worn; simple and stable } \\
\text { attached; and ability to obtain waveforms of angle, angular } \\
\text { velocity, and angular acceleration simply and with high } \\
\text { accuracy[51] }\end{array}$ & $\begin{array}{l}\text { Stability and } \\
\text { reliability remain } \\
\text { problematic [51] }\end{array}$ \\
\hline $\begin{array}{l}\text { Inertial } \\
\text { Motion Units } \\
\text { (IMUs, } \\
\text { Acceleration } \\
\text { plus angular } \\
\text { velocity) }\end{array}$ & Simple use & $\begin{array}{l}\text { Issues } \\
\text { concerning the } \\
\text { validity and } \\
\text { reliability of the } \\
\text { measurements }\end{array}$ \\
\hline $\begin{array}{l}\text { Camera- } \\
\text { based } \\
\text { methods }\end{array}$ & Simple use & $\begin{array}{l}\text { Difficult video } \\
\text { analysis }\end{array}$ \\
\hline
\end{tabular}

Searching the literature for suggestion of hardware or technologies to implement this test, and also for the chosen/best metric that gives enough sensitivity out of this test was not readily available. So in this 
review, we have tried to provide a complete list of all possible and clinic-friendly technologies for implementation of this test along with their main advantages and drawbacks. We have also tried to come up with a comprehensive list of outcome measures.

\subsection{Methods of implementation of pendulum test}

Since its introduction in 1951, the pendulum test was implemented using various devices or technologies, and in different groups of patients with spasticity. However, it took seven years until the first objective data collection was performed by Boczko and Mumenthaler using a battery-fed light and a video camera[28]. Most of the studies have focused on the spasticity at the knee joint, and a few tried to examine spasticity with pendulum test at elbow or ankle joints. In more than half a century, researchers have used this test in objective assessment of spasticity in many diseases including Stroke, Multiple Sclerosis (MS), Cerebral Palsy (CP), Spinal Cord Injury (SCI), lesions (cerebral or in central nervous system), paraplegia and hemiplegia, and trauma. Some of the studies compared healthy participants with their patient population. Almost half of these studies also used clinical scales either to choose the range of spasticity in their patient population $[16,29]$ or to compare their outcome measures according to the divisions that clinical scales provided[6, 17].Table 3 presents available studies that used pendulum test in chronological order, indicating the joint under study, participant groups, main technology for implementation of the test, and whether clinical scales are used in the study. There have been important theoretical studies such that Jikuya et al.[30] that have modeled spasticity during the pendulum test, or Kusuhara et al.[28] and Yamamoto et al.[31] that have theoretically examined advantages of using two linear accelerometers in pendulum test, but not included in the table because of no experimental data on patient population.

\section{Discussion}

\subsection{Technologies used in objective pendulum test}

Since the method of assessment of spasticity through pendulum test, and the processing steps to reach to the outcome measures are fully dependent on the implemented technology, this aspect is separately assessed in the literature. As Table 3 shows, variety of technologies, from ultrasound sensors[36] to camera-based[27, 50]or fiber-optic goniometers[49], have been used in the devices that implemented the test. However, some of these technologies are used more frequently whose advantages and disadvantages are compared in Table 4.

\subsection{Outcome measures of pendulum test}

Alongside development of technologies of implementation for pendulum test, numerous measures were suggested to classify the severity of spasticity as outcome measures. Wartenberg used the test qualitatively paying attention to irregularities in swinging time or the number of oscillations. suggested Resting position as his method's outcome measure. After that, many measures were introduced that are summarized in Table 5 . 
Table 5

Main categories of outcome measures (parameters) that are suggested in the studies that used pendulum test

\begin{tabular}{|c|c|c|c|c|}
\hline Signal & $\begin{array}{l}\text { Category } \\
\#\end{array}$ & Parameter & Measure/Parameter Definition & Ref. \\
\hline \multirow[t]{18}{*}{ Angle } & \multirow[t]{4}{*}{1} & Onset Ang & Angle at the start of test response & [18] \\
\hline & & A0 & $\begin{array}{l}\text { Knee angle at the beginning of the test during } \\
\text { maximal limb extension }\end{array}$ & $\begin{array}{l}{[13,} \\
38, \\
50]\end{array}$ \\
\hline & & as & Initial Knee angle & [44] \\
\hline & & Initial angle & & \\
\hline & \multirow[t]{11}{*}{2} & F1 Ang & Angle at the end of initial movement into flexion & $\begin{array}{l}{[18,} \\
49]\end{array}$ \\
\hline & & F1 Amp & F1 Ang - Onset Ang & $\begin{array}{l}{[18,} \\
49]\end{array}$ \\
\hline & & Ex & $\begin{array}{l}\text { First swing excursion: the difference between the } \\
\text { starting angle (the position at which the examiner } \\
\text { released the participant's heel) and the first angle } \\
\text { of reversal of the swinging limb }\end{array}$ & [53] \\
\hline & & P4 & First maximum of the oscillation & $\begin{array}{l}{[33,} \\
43]\end{array}$ \\
\hline & & FAR & $\begin{array}{l}\text { knee angle when shank motion first switched from } \\
\text { flexion to extension }\end{array}$ & [17] \\
\hline & & $\mathrm{A} 1$ & The amplitude of the first swing & {$[33$,} \\
\hline & & & Magnitude of first drop & \\
\hline & & $\phi \max$ & $\begin{array}{l}\text { The first maximum of the goniogram after } \\
\text { releasing the leg. }\end{array}$ & [50] \\
\hline & & ap & The peak angle of the first swing & [44] \\
\hline & & $\Theta 1$ & First maximum of the oscillation & $\begin{array}{l}{[6,} \\
39]\end{array}$ \\
\hline & & $\begin{array}{l}\text { First } \\
\text { reversal }\end{array}$ & & \\
\hline & \multirow[t]{3}{*}{3} & E1 Ang & $\begin{array}{l}\text { Angle at the end of initial movement into } \\
\text { extension }\end{array}$ & [33] \\
\hline & & E1 Amp & F1 Ang - E1 Ang & [33] \\
\hline & & $\mathrm{A} 2$ & $\begin{array}{l}\text { The angular change between the first minimum } \\
\text { and second maximum }\end{array}$ & $\begin{array}{l}{[45,} \\
50]\end{array}$ \\
\hline
\end{tabular}




\begin{tabular}{|c|c|c|c|c|}
\hline Signal & $\begin{array}{l}\text { Category } \\
\#\end{array}$ & Parameter & Measure/Parameter Definition & Ref. \\
\hline & \multirow[t]{5}{*}{4} & Rest ang & Resting knee angle & \multirow{3}{*}{$\begin{array}{l}{[17,} \\
6, \\
18, \\
35, \\
39]\end{array}$} \\
\hline & & $\begin{array}{l}\text { Rest } \\
\text { Angle(RA) }\end{array}$ & \multirow[t]{2}{*}{ Knee angle at the end of oscillations. } & \\
\hline & & $\theta r$ & & \\
\hline & & Plat Amp & Rest Ang - onset Ang & $\begin{array}{l}{[18,} \\
49]\end{array}$ \\
\hline & & af & Final position of the leg & [44] \\
\hline & \multirow[t]{5}{*}{5} & Duration & Duration of oscillations. & \multirow{2}{*}{$\begin{array}{l}{[6,} \\
42]\end{array}$} \\
\hline & & $\mathrm{T}$ & Test duration & \\
\hline & & $\begin{array}{l}\text { Relative } \\
\text { Swing Time }\end{array}$ & $\begin{array}{l}\text { The time between the peaks, Normalized to the } \\
\text { height of the person }\end{array}$ & $\begin{array}{l}{[16,} \\
27]\end{array}$ \\
\hline & & TFR & $\begin{array}{l}\text { Time to first reversal: time interval between the } \\
\text { start of shank motion and the first reversal from } \\
\text { flexion to extension. }\end{array}$ & [17] \\
\hline & & $\begin{array}{l}\text { Test } \\
\text { Duration }\end{array}$ & Duration from onset Angle to rest angle & [18] \\
\hline & \multirow[t]{6}{*}{6} & $\mathrm{~F}$ & Frequency of oscillations & \multirow{2}{*}{$\begin{array}{l}{[35,} \\
50]\end{array}$} \\
\hline & & & Frequency of the swing & \\
\hline & & C1 Freq & Initial cycle frequency $=1 /$ duration of E1 Ang & [18] \\
\hline & & $\begin{array}{l}\mathrm{N} \\
\mathrm{P} 2\end{array}$ & \multirow[t]{2}{*}{$\begin{array}{l}\text { The number of sinusoidal waves produced by the } \\
\text { swinging limb after the heel was released } \\
\text { (minimum of } 3 \text { degrees) }\end{array}$} & \multirow{2}{*}{$\begin{array}{l}{[6,} \\
33, \\
43, \\
46, \\
48]\end{array}$} \\
\hline & & & & \\
\hline & & Ncyc & $\begin{array}{l}\text { Number of cycles (full oscillations) was counted } \\
\text { between start of motion and until the oscillation } \\
\text { amplitudes is less than } 3 \text { degrees. }\end{array}$ & [39] \\
\hline & \multirow[t]{4}{*}{7} & RI & $\begin{array}{l}\text { Relaxation index: (starting angle - first angle) / } \\
\text { (starting angle - resting angle) }\end{array}$ & \multirow[t]{2}{*}{$\begin{array}{l}{[26,} \\
43, \\
48]\end{array}$} \\
\hline & & & F1 Amp / Plat Amp & \\
\hline & & & $\theta 1 / \theta r$ & [6] \\
\hline & & ERI & Extension Relaxation index = E1 Amp/ Plat Amp & $\begin{array}{l}{[18,} \\
49]\end{array}$ \\
\hline
\end{tabular}




$$
\begin{aligned}
& \text { Damping ratio. Defined as the ratio of the } \\
& \text { logarithmic decrement ( } \delta \text { ) to the period; expressed }
\end{aligned}
$$
in sec
$\lambda \quad$ Defined as the natural log of the second to fourth peak amplitude ratio

P1 Normalized relaxation index

Relaxation index at the half swing

Average relaxation index of 10 successive swings

Ratio 1

Ratio 1: $A 1 /(A 1-A 2)$, where $A 1$ is the amplitude

Ratio R1 of the first oscillation and $A 2$ is the amplitude of

$\mathrm{R} 1$ ratio the second oscillation.

Ratio R1: $A / B$, where $A$ is the amplitude of the first oscillation and $B$ is the amplitude of the second oscillation.

The amplitude of the first swing (A) divided by the amplitude of the rebound angle.

Ratio 2

Ratio 2: $A 1 / A 0$, where $A 0$ is the final resting angle

Ratio R2 and $\mathrm{A} 1$ is the amplitude of the first oscillation.

$\mathrm{R} 2$ ratio

R2: first swing (A) divided by the amplitude of the final position (C).

R2n

The normalized relaxation index. $\mathrm{R} 2 \mathrm{n}$ : $\mathrm{A} 1 / 1.6 \mathrm{~A} 0$ where $A 0$ is the knee angle between the full extension (starting position) and the neutral knee joint angle (end position), and A1 is the difference between the starting angle and the maximum flexion

\begin{tabular}{ll} 
AUC & $\begin{array}{l}\text { Area Under Curve: area between the knee angle } \\
\text { during oscillations and the resting angle; it is the } \\
\text { integral of the absolute value of the knee angle }\end{array}$ \\
\hline Ptotal & $\begin{array}{l}\text { The area between the goniogram and the time } \\
\text { axis. }\end{array}$ \\
\hline $\begin{array}{l}\text { Relative } \\
\text { area } \\
\text { difference }\end{array}$ & $\begin{array}{l}\text { Relative difference IP }+- \text { P-|/Ptotal between the } \\
\text { positive and negative areas and the total area } \\
\text { between the goniogram and the neutral line } \\
\text { starting from the first minimum }\end{array}$ \\
\hline
\end{tabular}




\begin{tabular}{|c|c|c|c|c|}
\hline Signal & $\begin{array}{l}\text { Category } \\
\#\end{array}$ & Parameter & Measure/Parameter Definition & Ref. \\
\hline & 9 & PT & $\begin{array}{l}\text { Total pendulum Score (combination of multiple } \\
\text { parameters) }\end{array}$ & [50] \\
\hline \multirow{9}{*}{$\begin{array}{l}\text { Angular } \\
\text { Velocity }\end{array}$} & \multirow[t]{4}{*}{1} & wmax & The maximum angular velocity of the shank & [50] \\
\hline & & Vmax & maximal velocity of the first swing $(\% / s)$ & $\begin{array}{l}{[16,} \\
26, \\
27]\end{array}$ \\
\hline & & F1 Vel & Maximum velocity during F1 Amp & [18] \\
\hline & & P7 & First maximum of the tachogram & [33] \\
\hline & \multirow[t]{2}{*}{2} & \multirow[t]{2}{*}{ VFR } & Velocity to first reversal: & \multirow{2}{*}{$\begin{array}{l}{[17,} \\
39]\end{array}$} \\
\hline & & & $\mathrm{VFR}=\mathrm{FAR} / \mathrm{TFR}$ & \\
\hline & \multirow[t]{3}{*}{3} & E1 Vel & Maximum velocity during E1 Amp & [18] \\
\hline & & P8 & First minimum the tachogram & [33] \\
\hline & & wmin & The minimum angular velocity of the shank & [50] \\
\hline \multirow[t]{3}{*}{$\begin{array}{l}\text { Angular } \\
\text { Acceleration }\end{array}$} & \multirow[t]{3}{*}{1} & $\mathrm{~F} 1 \mathrm{~A} / \mathrm{D}$ ratio & $\begin{array}{l}\text { Initial flexion acceleration/deceleration ratio = Max } \\
\text { acceleration duration F1 Amp/ Max deceleration } \\
\text { during F1 Amp }\end{array}$ & [18] \\
\hline & & $\begin{array}{l}\text { First } \\
\text { Maximum } \\
\text { Acceleration }\end{array}$ & First Maximum Acceleration during flexion phase & [26] \\
\hline & & $\begin{array}{l}\text { Max Acc on } \\
\text { the rebound } \\
\text { swing }\end{array}$ & Max Acceleration during extension phase & [26] \\
\hline
\end{tabular}

The first mentioned set of outcome measures from pendulum test of spasticity on the knee were by Boczko et al.[25] in 1950s. During the following half a century, other than number of oscillations, test duration and peak angles, other measures such as relaxation index (RI) were introduced to have higher reliability. The most comprehensive works on outcome measures during this time were performed by Bajd et al.[33, 46, 47]and Stillman et al.[18]. Table 5 illustrates all categories of outcome measures that have been suggested in the literature of pendulum test of spasticity. The three main categories are parameters based on angle data, based on angular velocity, and finally based on angular acceleration. All the investigated studies have used outcome measures that are based on joint angle during the test. Almost half of the studies have used parameters that are based on angular data (Table 5). A considerable amount of the studies has used more than one category (Table 5).

Overall, the suggested parameters can be divided into two categories of primary and secondary Loading [MathJax]/jax/output/CommonHTML/fonts/TeX/fontdata.js spects of the collected data such as the peak 
value of an angle, or number of oscillations (for example the first six categories in Table 5 for parameters based on angle data). Secondary outcome measures are calculated or combined from the primary ones mainly to reduce the number of parameters and to come up with ones that are more sensitive or better illustrate level of spasticity.

Outcome measures that are based on angle data are divided into 9 categories in Table 5. Category \#1 is based on the initial position of the extended knee in the test. Although $29 \%$ of studies (out of 17 that we have investigated) have used this category in their set of parameters, it is not an outcome measure of spasticity test by itself, but is mainly used in the calculation of other outcome measures. Second category is used by $71 \%$ of the studies and relies on the maximum flexion angle in the first swing after the leg release. Category \#3 examines the max angle in the first rebound towards extension of the knee, which is used by $18 \%$ of the studies. Resting angle or the final position of the leg is category $\# 4$ and is used by $41 \%$ of the literature. Category \#5 examines durations in the test, whether overall duration or the time between two specific points, and is used by $35 \%$ of the studies. Number of cycles or frequency is category \#6 and is used by $59 \%$ investigators. In counting the oscillations, a threshold of three degrees is considered below which the oscillations are ignored. Frequency concept was either used as the inverse of the time duration for the first cycle, or as the ratio of the number of total cycles to the total time. Time and frequency categories could be based on angular velocity or acceleration during the test, but almost all the researchers have based them on the angle data. Categories \#7-9 are secondary measures and are calculated from the previous categories. Category \#7 examines the ratio of the amplitudes for various angles. Wide range of ratios have been suggested by researchers and almost all studies (94\%) have used at least one such category of outcome measure. Most of the powerful and consistent outcome measure that were capable of identifying levels of spasticity were in this category $[44,45]$. Category \#8 uses area under the knee angle curve which considers positive and negative values for flexion and extension around the resting angle, and is used by $24 \%$ of the studies. Recently, Popovic et al. suggested a total score for pendulum test which takes many aspects of the angle cure into account and comes up with a final score[50]. This is category \#9 in Table 5.

There are three categories of outcome measures in the angular velocity group. Category \#1 uses the first maximum angular velocity in the flexion direction, and is used by $35 \%$ of the investigators. Category \#2 relies on the average angular velocity in the first swing towards the flexion, and is used by $12 \%$ of the literature. Category \#3 is based on the first maximum velocity in the rebound towards the knee extension, and is suggested by the $18 \%$ of the literature. Some of the researchers call this category the minimum velocity instead of maximum velocity in the opposite direction.

Few studies have used outcome metrics that rely on angular acceleration. Stillman et al.[18] suggested the ratio of maximum acceleration to maximum deceleration during the first swing towards flexion of the knee as their measure of spasticity. Maximum angular acceleration both in flexion and in extension phases are separately used as outcome measures by Brown et al.[26] in 1988. 
As can be seen from the table, quite a lot of parameters have been suggested as outcome measures. However, it is not practical to use all of the suggested parameters, and unfortunately no study has compared all these parameters to provide a comprehensive subjective scale of strength/weakness points. None the less, some of the studies have chosen reasonable number of outcome measure (and some provided a rationale for their choice). Table 6 is the list of the main studies on the outcome measures of pendulum test that is used in this review.

Table 6

Sets of outcome measures that were proposed in each key study

\begin{tabular}{|c|c|c|}
\hline $\begin{array}{l}\text { \# of used } \\
\text { parameters }\end{array}$ & List of Parameters (Measures) & First author \\
\hline 8 & p1-p8 (using A0, A1, A2, R1,R2,R2n) & Bajd [33] \\
\hline 6 & Ex, RI, $\beta, \lambda, t, n$ & Szopa[42] \\
\hline 4 & p1, p2, p4, p5 & Yeh[43] \\
\hline 1 & R2n index (using af, as, ap) & $\begin{array}{l}\text { Vargas Luna } \\
{[44]}\end{array}$ \\
\hline 4 & RI, Test duration, Fang, Rest ang & Azevedo[41] \\
\hline 2 & Ratio 1 \& Ratio 2 & Bui[45] \\
\hline 1 & PT score & $\begin{array}{l}\text { Popovic- } \\
\text { Maneski[50] }\end{array}$ \\
\hline 2 & Ratio R1, Ratio R2 & Leslie[34] \\
\hline 5 & $\Theta 1, N$, Duration, Rl, $\theta \mathrm{r}$ & $\begin{array}{l}\text { Greenan } \\
\text { Fowler[6] }\end{array}$ \\
\hline 4 & R2 ratio, R1 ratio, Vmax, Relative swing time & Nordmark[16] \\
\hline 4 & First Reversal, AUC, VFR, Resting Angle & Bohannon[39] \\
\hline 5 & FAR, IA, AUC, TFR, VFR & Sterpi[17] \\
\hline 14 & $\begin{array}{l}\text { On Ang, Rest Ang, F1 Ang, E1 Ang, F1 Amp, E1 Amp, plat Amp, RI, ERI, } \\
\text { F1 Vel, E1 Vel, F1 A/D ratio, Duration, C1 Freq }\end{array}$ & Stillman[18] \\
\hline 5 & F1 Amp, E1 Amp, plat Amp, RI, ERI & Tancredo[29] \\
\hline 4 & $\begin{array}{l}\text { RI, Vmax, First Maximum Acceleration, Max Acc on the rebound } \\
\text { swing }\end{array}$ & Brown[26] \\
\hline 3 & A0, A1, Resting Angle & $\mathrm{He}[35]$ \\
\hline 6 & RI, ERI, F1Amp, E1Amp, Plat, Ncyc & Whelan[49] \\
\hline
\end{tabular}

In the literature of the pendulum test for spasticity, there is no standard agreement between the 
different references used for measuring the knee angle. Overall, four key positions can be used as a reference: Horizontal plane, vertical plane, initial shank position, and final shank position in the test. Figure 3-a shows these four possible frames of reference for knee angle, along the first four categories of angle parameters in Table 5.

Most of the studies have used horizontal plane as their frame of reference[6, 16-18, 26, 29, 34, 42]. The second most popular frame of reference for angular movement is rest angle or the final position of the knee in the pendulum test[27, 33, 35, 36, 43,50]. Some of the researchers have used the initial angle of the shank as their reference instead of horizontal plane[39, 45, 49]. No researcher has used vertical plane as their reference in knee angle measurement. One example of such ambiguity is A0 which depending on the reference is defined as "Final resting angle" [45] as well as "knee angle at the beginning of the test during maximal limb extension" [17,35]. Similarly, differences can be observed in the definition of other spasticity measures such is definition of $\mathrm{RI}$ in $[6,18]$ and in $[33,43]$.

Figures 3-b illustrate two typical knee angle traces during a pendulum test. The bold trace corresponds to when the reference is the resting angle. Sections of knee angle trace, that parameters (angle outcome measures) in categories \#1-\#4 are extracted, are marked. The dotted trace corresponds to when the reference is horizontal plane. If the beginning of trace falls on the time axis, then the reference is initial angle.

\section{Conclusions}

This systematic review aimed at analyzing the state of the art in implementation of Pendulum test and the outcome measures of this method of evaluation of spasticity. This test is agreed to be repeatable and a valid method of identifying presence of spasticity[27, 39], though it may not be successful in discriminating between close levels of spasticity[49]. Since lower leg weight is suitable to create enough speed through free fall in the pendulum test, which is crucial for this speed dependent symptom, most of this test's applications is on the knee joint. However, using extra weight and special apparatus, this test can be applied to other joints such as elbow[38].

Non-instrumented pendulum test lacks objectivity and is apparently not used much by researchers. Instrumented pendulum test using multitudes of sensor technologies have been reported in the literature and evaluated as a feasible method of objective assessment of spasticity particularly for the knee extensors $[18,54,55]$.

Sensor technologies that are used for implementation of this test (Tables 1,2) would affect reliability/repeatability, ease and speed of setup, size and hindrance to pendular movement and hence suitability for clinical use, susceptibility to interfering factors such as gravity, ease of data processing and analysis and hence possibility of implementation in stand-alone devices. Overall, in the past few decades, the most technology been used is goniometer and electro-goniometer. Choice of sensor affects the type of signal that is used in data collection and thereby in outcome measure for the test. Although,

Loading [MathJax]/jax/output/CommonHTML/fonts/TeX/fontdata.js prm angle data to angular velocity or

Page 17/26 
acceleration. As can be seen in Table 5, all of the studies that we found to provide objective assessment method of spasticity with outcome metrics, used angular data. Almost half of them have also used angular data whether using tachometer/gyroscopes or differentiating angular data. Finally, almost $10 \%$ of the studies have focused on angular acceleration data as well.

We have categorized all 33 outcome measures that appeared in the literature into 13 categories in Table 5. These measures/metrics are supposed to help pendulum test differentiate between healthy and various levels of spasticity in the joint under consideration. Some of the studies have commented on the sensitivity of single outcome measures $[6,49,56]$. Each of the studies we investigated utilized between one to 14 outcome measures (Table 6).

Most of the studies have used more than one measure and argue that no single measure can represent all abnormal aspects of passive resistance of the disordered joint to the movement[18]. Unfortunately, there has been no study that optimizes a model using all or some of these 33 measures and comes up with a single combined measure with the highest discriminative power. Although such a model might be different for various spastic groups of patients. Nonetheless, some of the studies have tried such modeling approach without doing the optimization step. For example, Whelan et al. tried two models to find presence of knee spasticity in four different patient cohorts[49]. Another example is the attempt by popovic-Maneski et al.[50] in providing a single measure called global measure of spasticity.

Finally, such metrics that come out of pendulum test is supposed to be used by clinicians and should prove its power in a comparison by their golden clinical measures. Out of 5 clinical scales that are mentioned in studies we investigated, MAS and AS were the mostly used ones (Table 3). However, a modeling study that provides a relationship between such clinical scale as a gold standard and a single/combined outcome measure is really missing.

In this review we tried to come up with a comprehensive list of outcome measures along with the suggested sets of measures by lead researchers in this field (Table 5-6). We tried to provide standardized definitions for outcome measures through 13 categories for three type of signals (Table 5). However, it seems that a thorough modeling study is still missing. One that tries to take all of the 33 outcome measures into account and provides the best minimal sets of necessary parameters. Such final model, if provided, will accelerate making acceptable clinical device for objective assessment of spasticity.

\section{Abbreviations}

CSI: Composite Spasticity Index; HAT:Hypertonia Assessment Tool; TSS:triple Spasticity Scale; AS:Ashworth Scale; MAS:Modified Ashworth Scale; TS:Tardieu Scale; MTS:Modified Tardieu Scale; ROM:Range Of Motion; MS:Multiple Sclerosis; CP:Cerebral Palsy; SCl:Spinal Cord Injury; Rl:Relaxation Index; NC:No Comparison; CP:Cerebral Palsy; MS:Multiple Sclerosis; SCl:Spinal Cord Injury; DS:Degenerative Syndromes of the nervous system; NR:Not report in original paper; PTD:Pendular Test Device; DAROM:Dynamic Evaluation of Range of Motion scale; AIS:Association Impairment Scale; 
ABI:Acquired Brain Injury; SDR:Spastic Diplegia undergoing selective dorsal Rhizotomy; Ang:Angle; AMP:Amplitude; Ex:Excursion; TFR:Time of first reversal; F, Freq:Frequency; N:Number of oscillation; Ncycle:Number of cycle; ERI:Extension Relaxation Index; AUC:Area Under Curve; Vel:Velocity; PT:Total Pendulum Score; RA:Rest Angle;

\section{Declarations}

\section{Ethics approval and consent to participate}

Not applicable.

\section{Consent for publication}

Not applicable.

\section{Availability of data and materials}

The generated or analyzed data during this study are all included in the published article.

\section{Competing interests}

The authors declare that they have no competing interests.

\section{Funding}

No commercial company was involved in this study and no external sources of funding were used.

\section{Author's contributions}

FR and RE conceived the work and designed the article. RE and NS performed the literature review. FR and RE wrote and revised the manuscript. FR, MRA, and NS edited the manuscript. FR supervised the work. All authors read and approved the final manuscript.

\section{Acknowledgements}

Not applicable. 
1Department of Electrical Engineering, Faculty of Engineering, University of Bonab, Bonab, Iran. 2Department ofElectronic, Faculty of Electrical and Computer Engineering, University of Tabriz, Tabriz, Iran. 3Department ofBiomechanical Engineering, Faculty of Biomedical Engineering, Sahand University of Technology, Tabriz, Iran

\section{References}

1. Pandyan A, Gregoric M, Barnes M, Wood D, Wijck F, Van, Burridge J, et al. Spasticity: Clinical perceptions, neurological realities and meaningful measurement. Disabil Rehabil. 2005;27:2-6. doi:10.1080/09638280400014576.

2. Simpson DM, Gracies JM, Yablon SA, Barbano R, Brashear A. Botulinum neurotoxin versus tizanidine in upper limb spasticity: a placebo-controlled study. J Neurol Neurosurg Psychiatry. 2008;80:380-5. doi:10.1136/jnnp.2008.159657.

3. Kirshblum S. Treatment alternatives for spinal cord injury related spasticity. J Spinal Cord Med. 1999;22:199-217. doi:10.1080/10790268.1999.11719570.

4. Sheean G. The pathophysiology of spasticity. Eur J Neurol. 2002;9(Suppl 1):3. 9-61. doi:10.1088/1751-8113/44/8/085201.

5. Mayer $\mathrm{NH}$. Clinicophysiologic concepts of spasticity and motor dysfunction in adults with an upper motoneuron lesion. Muscle Nerve Suppl. 1997;6:1-13.

6. Greenan Fowler E, Nwigwe Al, Wong Ho T. Sensitivity of the pendulum test for assessing spasticity in persons with cerebral palsy. Dev Med Child Neurol. 2000;42:0012162200000323. doi:10.1017/S0012162200000323.

7. Burke D. Spasticity as an adaptation to pyramidal tract injury. Adv Neurol. 1988;47:401-23. http://www.ncbi.nlm.nih.gov/pubmed/3278524. Accessed 1 Aug 2018.

8. $10.1109 /$ HIC.2016.7797723

Jonnalagedda P, Deng F, Douglas K, Chukoskie L, Yip M, Ng TN, et al. An instrumented glove for improving spasticity assessment. In: 2016 IEEE Healthcare Innovation Point-Of-Care Technologies Conference (HI-POCT). IEEE; 2016. p. 167-70. doi:10.1109/HIC.2016.7797723.

9. Calota A, Feldman AG, Levin MF. Spasticity measurement based on tonic stretch reflex threshold in stroke using a portable device. Clin Neurophysiol. 2008;119:2329-37.

10. Decq P, Filipetti P, Lefaucheur JP. Evaluation of spasticity in adults. Oper Tech Neurosurg. 2004;7:100-8. 3 SPEC. ISS..

11. ASHWORTH B. PRELIMINARY TRIAL OF CARISOPRODOL IN MULTIPLE SCLEROSIS. Practitioner. 1964;192:540-2.

12. Bohannon R, Smith M. Interrater Reliability of a Modified Ashworth Sclae Of Muscle Spasticity. Class Pap Orthop. 1987;:415-7.

13. TARDIEU G, SHENTOUB S. DELARUE R. [Research on a technic for measurement of spasticity]. Rev

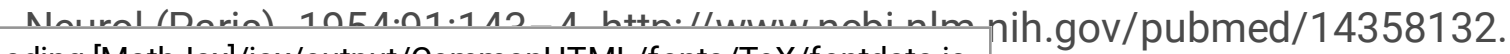


14. Boyd RN, Graham HK. Objective measurement of clinical findings in the use of botulinum toxin type A for the management of children with cerebral palsy. Eur J Neurol. 1999;6 Suppl:4:s23-35. doi:10.1111/j.1468-1331.1999.tb00031.x.

15. Wartenberg R. Pendulousness of the Legs as a Diagnostic Test. Neurology. 1951;1:18-8. doi:10.1212/wnl.1.1.18.

16. $10.1111 /$ j.1469-8749.2002.tb00255.x

Nordmark E, G.Andersson. Wartenberg pendulum test: Objective quantification of muscle tone in children with spastic diplegia undergoing selective dorsal rhizotomy. Dev Med Child Neurol. 2002;44:26-33. https://onlinelibrary.wiley.com/doi/pdf/10.1111/j.1469-8749.2002.tb00255.x. Accessed 5 Apr 2019.

17. Sterpi I, Caroli A, Meazza E, Maggioni G, Pistarini C, Colombo R. Lower limb spasticity assessment using an inertial sensor: a reliability study. Physiol Meas. 2013;34:1423-34. doi:10.1088/09673334/34/11/1423.

18. Stillman B, McMeeken J. A video-based version of the pendulum test: Technique and normal response. Arch Phys Med Rehabil. 1995;76:166-76.

19. Flamand V, MassÃ@)-Alarie H, Schneider C. Psychometric evidence of spasticity measurement tools in cerebral palsy children and adolescents: A systematic review. J Rehabil Med. 2013;45:14-23. doi:10.2340/16501977-1082.

20. Bar-On L, Aertbeliën E, Molenaers G, Dan B, Desloovere K. Manually controlled instrumented spasticity assessments: a systematic review of psychometric properties. Dev Med Child Neurol. 2014;56:932-50. doi:10.1111/dmcn.12419.

21. Biering-Sørensen F, Nielsen JB, Klinge K. Spasticity-assessment: A review. Spinal Cord. 2006;44:70822.

22. Poon DMY, Hui-Chan CWY. Hyperactive stretch reflexes, co-contraction, and muscle weakness in children with cerebral palsy. Dev Med Child Neurol. 2009;51:128-35.

23. ALBRIGHT L, ANDREWS M. Development of the Hypertonia Assessment Tool (HAT). Dev Med Child Neurol. 2009;52:411-2. doi:10.1111/j.1469-8749.2009.03477.x.

24. Li F, Wu Y, Xiong L. Reliability of a new scale for measurement of spasticity in stroke patients. J Rehabil Med. 2014;46:746-53.

25. Boczko M, Mumenthaler M. Modified pendulousness test to assess tonus of thigh muscles in spasticity. Neurology. 1958;8:846-6. doi:10.1212/wnl.8.11.846.

26. Brown RA, Lawson DA, Leslie GC, Part NJ. Observations on the applicability of the Wartenberg pendulum test to healthy, elderly subjects. J Neurol Neurosurg Psychiatry. 1988;51:1171-7. doi:10.1136/jnnp.51.9.1171.

27. Syczewska M, Lebiedowska MK, Pandyan AD. Quantifying repeatability of the Wartenberg pendulum test parameters in children with spasticity. J Neurosci Methods. 2009;178:340-4. doi:10.1016/j.jneumeth.2008.12.031. 
28. Kusuhara T, Jikuya K, Nakamura T, Michinishi H, Yamamoto Y, Okamoto T. Detection of knee-joint motions using two linear accelerometers for pendulum test. Electron Commun Japan. 2012;95:41-8. doi:10.1002/ecj.11383.

29. Tancredo JR, Maria RM, Azevedo ERFBM de, Alonso KC, Varoto R, Cliquet Junior A. Clinical assessment of spasticity in individuals with spinal cord injury. Acta Ortopédica Bras. 2013;21:310-4. doi:10.1590/S1413-78522013000600002.

30. Jikuya K, Michinishi H, Nakamura T, Kusuhara T, Yamamoto Y, Okamoto T. A detailed model for knee joint acceleration motions obtained by pendulum test. IFMBE Proc. 2009;25:472-5.

31. $10.5772 / 37468$

Yamamoto Y, Jikuya K, Kusuhara T, Nakamura T, Michinishi H, Okamoto T. Precise Measurement System for Knee Joint Motion During the Pendulum Test Using Two Linear Accelerometers. In: Advanced Topics in Measurements. InTech; 2012. p. 19-42. doi:10.5772/37468.

32. Couvée LMJ, van der Laarse WD, Oosterveld WJ. Clinical experiences on spasticity with a modification of the Mumenthaler Pendulum Test. Paraplegia. 1968;6:96-102. doi:10.1038/sc.1968.17.

33. Bajd T, Vodovnik L. Pendulum testing of spasticity. J Biomed Eng. 1984;6:9-16.

34. Leslie G, Muir C, Part N, Roberts R. A comparison of the assessment of spasticity by the Wartenberg pendulum test and the Ashworth grading scale in patients with multiple sclerosis. Clin Rehabil. 1992;6:41-8. doi:10.1177/026921559200600106.

35. He J, Norling WR, Wang Y. A dynamic neuromuscular model for describing the pendulum test of spasticity. IEEE Trans Biomed Eng. 1997;44:175-84. doi:10.1109/10.554764.

36. Kaeser HE, Gihring H, Bergmann R, Gfhring I, Wachter KC, Ettlin TM. Testing an Antispasticity Drug (Tetrazepam) with the Pendulum Test: A Monocentric Pilot Study. Neurorehabil Neural Repair. 1998;12:169-77. doi:10.1177/154596839801200405.

37. Le Cavorzin P, Hernot X, Bartier O, Allain H, Carrault G, Rochcongar P, et al. A computed model of the pendulum test of the leg for routine assessment of spasticity in man. ITBM-RBM. 2001;22:170-7. doi:10.1016/S1297-9562(01)90028-2.

38. Lin C-C, Ju M-S, Lin C-W. The pendulum test for evaluating spasticity of the elbow joint. Arch Phys Med Rehabil. 2003;84:69-74. doi:10.1053/apmr.2003.50066.

39. Bohannon RW, Harrison S, Kinsella-Shaw J. Reliability and validity of pendulum test measures of spasticity obtained with the Polhemus tracking system from patients with chronic stroke. J Neuroeng Rehabil. 2009;6:30. doi:10.1186/1743-0003-6-30.

40. 10.1109/EMBC.2013.6610586

LeMoyne R, Mastroianni T, Grundfest W, Nishikawa K. Implementation of an iPhone wireless accelerometer application for the quantification of reflex response. In: 2013 35th Annual International Conference of the IEEE Engineering in Medicine and Biology Society (EMBC). IEEE; 2013. p. 4658-61. doi:10.1109/EMBC.2013.6610586. 
41. Azevedo E, Alonso K, Maria R, Beinotti F, Cliquet A. Posture influence on the pendulum test of spasticity in spinal cord injured patients. J Neurol Sci. 2013;333:e567. doi:10.1016/j.jns.2013.07.1987.

42. Szopa A, Domagalska-Szopa M, Kidoń Z, Syczewska M. Quadriceps femoris spasticity in children with cerebral palsy: measurement with the pendulum test and relationship with gait abnormalities. $J$ Neuroeng Rehabil. 2014;11:166. doi:10.1186/1743-0003-11-166.

43. Yeh $\mathrm{C}-\mathrm{H}$, Hung $\mathrm{C}-\mathrm{Y}$, Wang $\mathrm{Y}-\mathrm{H}$, Hsu W-T, Chang Y-C, Yeh J-R, et al. Novel application of a Wii remote to measure spasticity with the pendulum test: Proof of concept. Gait Posture. 2016;43:70-5. doi:10.1016/j.gaitpost.2015.10.025.

44. Vargas Luna JL, Guðfinnsdóttir HK, Magnúsdóttir G, Guðmundsdóttir V, Krenn M, Mayr W, et al. Effects of sustained electrical stimulation on spasticity assessed by the pendulum test. Curr Dir Biomed Eng. 2016;2:405-7. doi:10.1515/cdbme-2016-0090.

45. Bui HT, Gagnon C, Audet O, Mathieu J, Leone M. Measurement properties of a new wireless electrogoniometer for quantifying spasticity during the pendulum test in ARSACS patients. J Neurol Sci. 2017;375 January:181-5. doi:10.1016/j.jns.2017.01.065.

46. Popović-Maneski L, Aleksić A, Čobeljić R, Bajd T, Popović DB. a New Method and Instrumentation for Analyzing Spasticity. IETI Trans Ergon Saf. 2017;1:12-27. http://ieti.net/TES/2017V1I103.html.

47. Aleksić A, Graovac S, Maneski LP, Popović DB. The assessment of spasticity: Pendulum test based smart phone movie of passive markers. Serbian J Electr Eng. 2018;15:29-39.

48. Popovic D, Bajd T. Pendulum test: Quantified assessment of the type and level of spasticity in persons with central nervous system lesions. Serbian J Electr Eng. 2018;15:1-12. doi:10.2298/SJEE171204006P.

49. Whelan A, Sexton A, Jones M, O'Connell C, McGibbon CA. Predictive value of the pendulum test for assessing knee extensor spasticity. J Neuroeng Rehabil. 2018;15:68. doi:10.1186/s12984-018-0411$\mathrm{x}$.

50. Popovic-Maneski L, Aleksic A, Metani A, Bergeron V, Cobeljic R, Popovic DB. Assessment of Spasticity by a Pendulum Test in SCI Patients Who Exercise FES Cycling or Receive only Conventional Therapy. IEEE Trans Neural Syst Rehabil Eng. 2018;26:181-7.

51. Haq Z. Advanced Topics in Measurements. 2012.

52. Lin Y-C, Lin I-L, Chou T-FA, Lee H-M. Quantitative evaluation for spasticity of calf muscle after botulinum toxin injection in patients with cerebral palsy: a pilot study. J Neuroeng Rehabil. 2016;13:25. doi:10.1186/s12984-016-0135-8.

53. 10.1109/EMBC.2016.7591777

Choi S, Kim J. Improving modified tardieu scale assessment using inertial measurement unit with visual biofeedback. In: 2016 38th Annual International Conference of the IEEE Engineering in Medicine and Biology Society (EMBC). IEEE; 2016. p. 4703-6. doi:10.1109/EMBC.2016.7591777.

54. Jamshidi M, Smith AW. Clinical measurement of spasticity using the pendulum test: Comparison of Loading [MathJax]/jax/output/CommonHTML/fonts/TeX/fontdata.js S Med Rehabil. 1996;77:1129-32. 
55. Valle MS, Casabona A, Sgarlata R, Garozzo R, Vinci M, Cioni M. The pendulum test as a tool to evaluate passive knee stiffness and viscosity of patients with rheumatoid arthritis. BMC Musculoskelet Disord. 2006;7.

56. Bajd T, Bowman B. Testing and modelling of spasticity. J Biomed Eng. 1982;4:90-6.

\section{Figures}

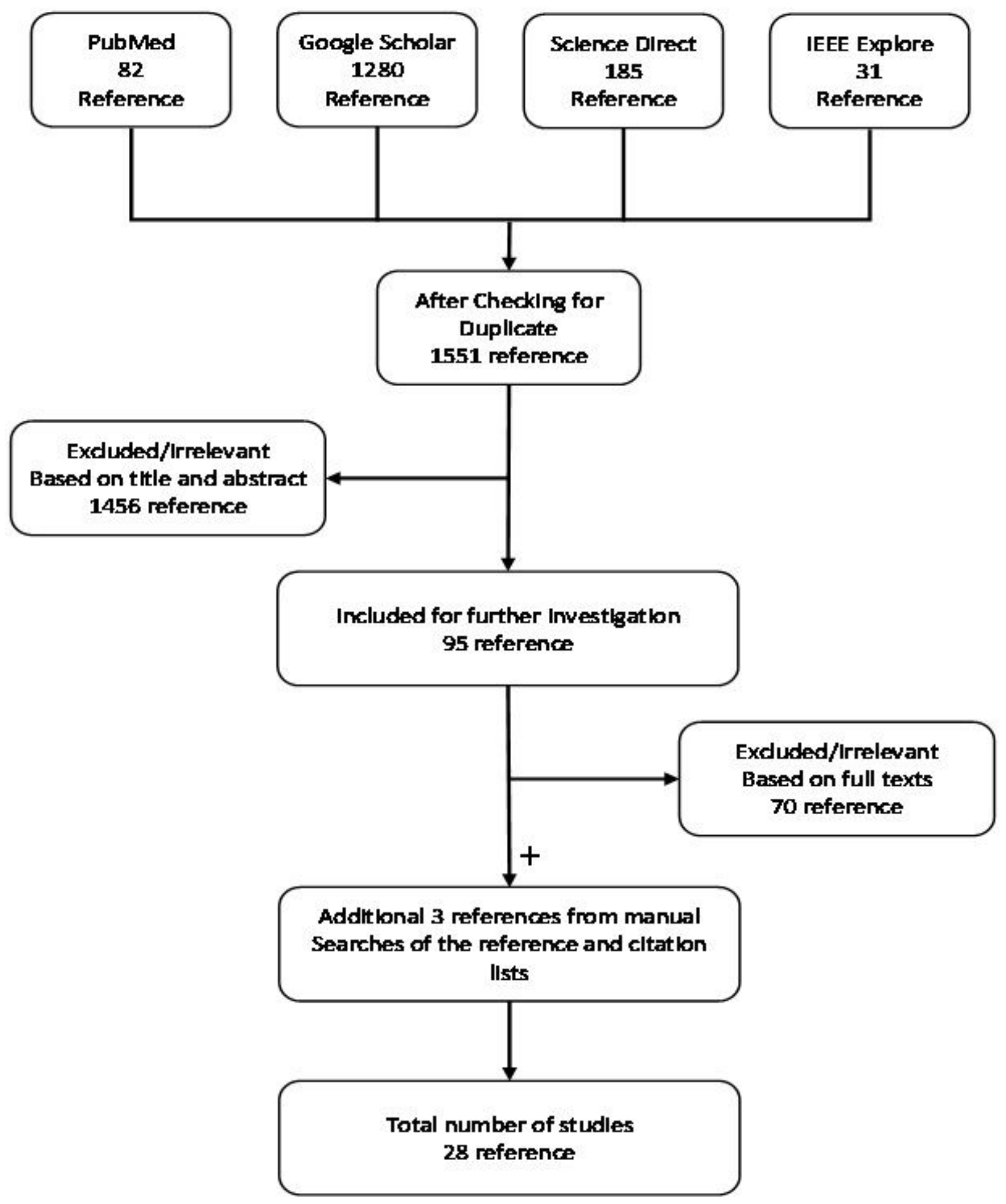


Flow chart of the search and selection process of the systematic review of Objective assessment of spasticity by pendulum test for methods of implementation and outcome measures

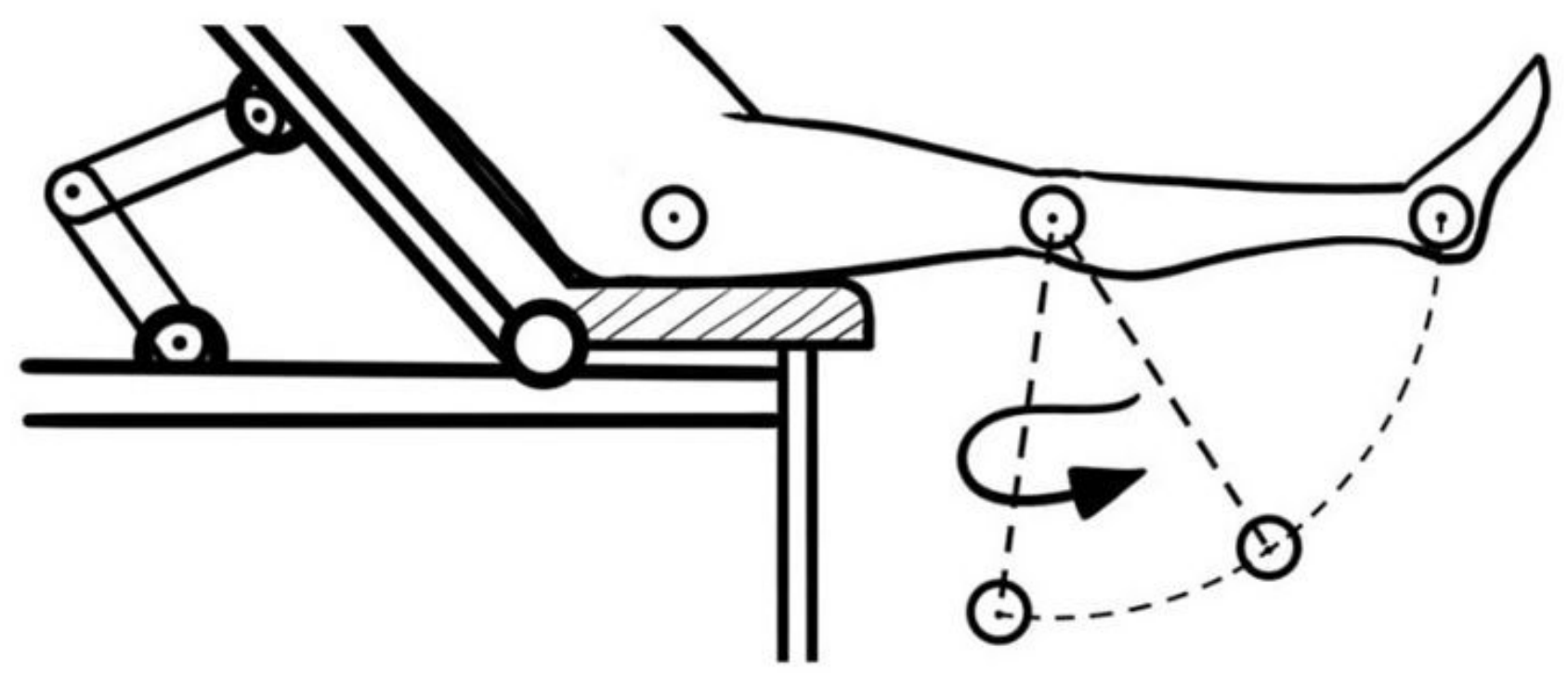

Figure 2

Experimental setup for pendulum test of spasticity at the knee level
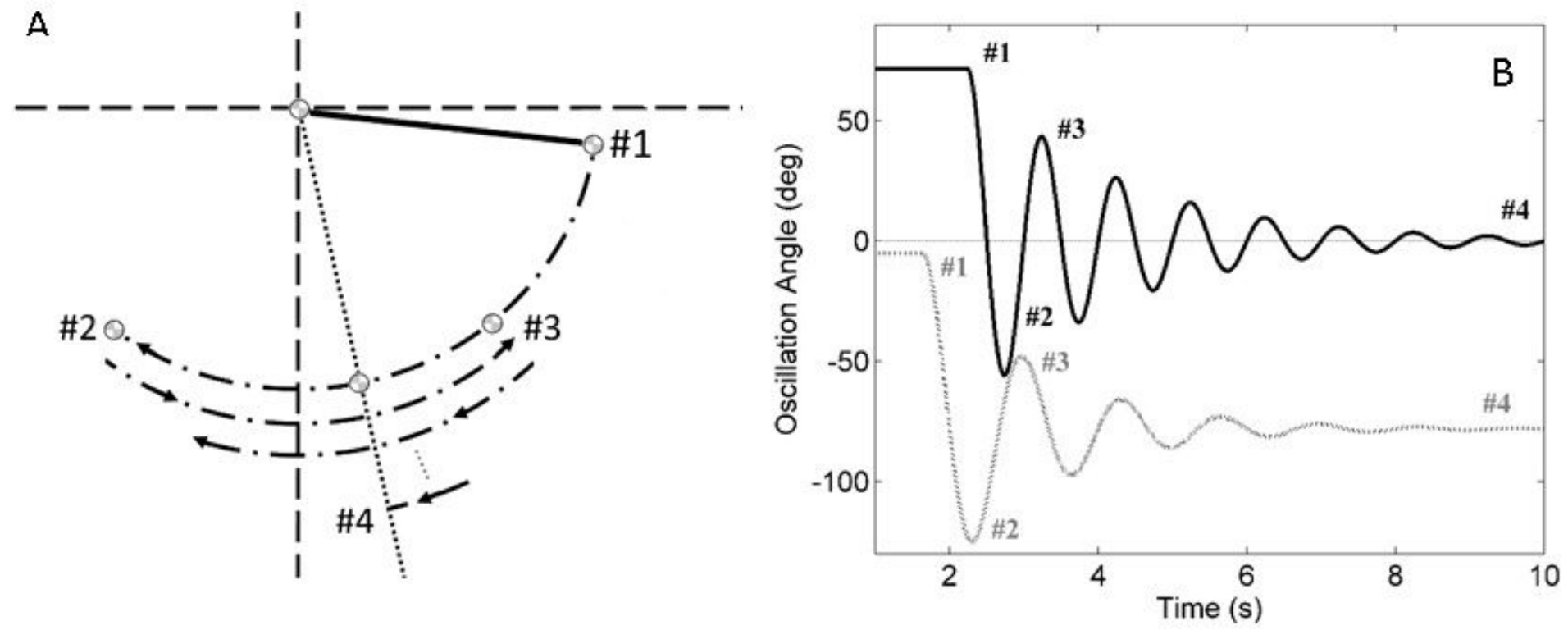

Figure 3

a) The first couple of swing traces along the first four category of outcome measures (\#1-\#4) that are key joint angles during the pendulum test and explained in Table 5. b) Time series for the knee joint angle Loading [MathJax]/jax/output/CommonHTML/fonts/TeX/fontdata.js 
during the pendulum test along the first four category of outcome measures. The bold trace corresponds to when the reference is the resting angle. The dotted trace corresponds to when the reference is horizontal plane. 